\title{
THE CONNECTIVE TISSUE REACTION AROUND IMPLANTED PELLETS OF STEROID HORMONES ${ }^{1}$
}

\author{
BURTON L. BAKER \\ Department of Anatomy, University of Michigan Medical School, \\ Ann Arbor, Michigan \\ SEVEN FIGURES
}

It is established that cortisone and hydrocortisone may prevent inflammation but their precise mode of action remains unknown. Therefore, it is desirable to examine the histological modifications which these hormones elicit in connective tissue under varied experimental conditions. This investigation has two objectives, the first being to compare the changes which occur in connective tissue surrounding implanted pellets of cortisone with those which appear near implanted pellets of other steroid substances. A second aim was to study the effect of subcutaneously injected adrenocortical and gonadal hormones on the foreign body reaction elicited by implanted pellets of cholesterol. The first objective is particularly important because implantation of pellets is a potentially useful method of administering cortisone or hydrocortisone in clinical therapy.

\section{MATERIALS AND METHODS}

For study of the local reactions induced by steroid hormones, pellets of several steroid substances, weighing 0.5 to $1.5 \mathrm{mg}$, were implanted in the orbital connective tissue of adult rats through a small slit in the conjunctival sac. Each of 16 rats

${ }^{1}$ Supported in part by research grants (A-131) from the National Institutes of Health, Public Health Service, Merek and Co., Ine., and The Upjohn Company. 
received one pellet of cortisone ${ }^{2} ; 16,11$-desoxycorticosterone; 12, testosterone; 10, alpha-estradiol ; and 17, cholesterol. Since cholesterol is not known to possess the physiological properties of a hormone, the reaction induced by pellets of cholesterol was used as a basis for comparison with the effects elicited by the hormones. Although sterilized pellets of cortisone were not available, the implantations were carried out under as

TABLE 1

Number, sex, and body weights of the rats used

\begin{tabular}{|c|c|c|c|c|c|}
\hline TREATMENT & $\begin{array}{l}\text { No. OF } \\
\text { RATS }\end{array}$ & sex & $\begin{array}{l}\text { DAILY } \\
\text { DOSE }\end{array}$ & $\begin{array}{c}\text { BODY WhIGHT } \\
\text { Initial }\end{array}$ & Final \\
\hline & & & & $g m$ & $g m$ \\
\hline Cortisone acetate & 3 & 9 & $5 \mathrm{mg}$ & $223 \pm 13^{1}$ & $196 \pm 13$ \\
\hline Vehicle no. 1 & 3 & $q$ & $1 \mathrm{~cm}^{3}$ & $230 \pm 15$ & $225 \pm 14$ \\
\hline Cortisone acetate & 3 & $\sigma^{*}$ & $5 \mathrm{mg}$ & $389 \pm 22$ & $371 \pm 13$ \\
\hline $0.9 \% \mathrm{NaCl}$ & 3 & $\delta^{2}$ & $1 \mathrm{~cm}^{3}$ & $327 \pm 4$ & $332 \pm 15$ \\
\hline Testosterone prop. & 6 & $\delta$ and $q$ & $5 \mathrm{mg}$ & $265 \pm 46$ & $277 \pm 49$ \\
\hline $\mathrm{DCA}$ & 6 & $\delta$ and $q$ & $5 \mathrm{mg}$ & $289 \pm 59$ & $294 \pm 70$ \\
\hline Sesame oil & 6 & $\delta$ and $q$ & $1 \mathrm{~cm}^{3}$ & $259 \pm 38$ & $265 \pm 44$ \\
\hline Estradiol dip. & 3 & $\delta$ & $40 \mu \mathrm{g}$ & $361 \pm 24$ & $321 \pm 16$ \\
\hline Sesame oil & 3 & $\sigma^{2}$ & $.5 \mathrm{~cm}^{3}$ & $362 \pm 15$ & $335 \pm 13$ \\
\hline Estradiol dip. & 3 & $q$ & $80 \mu \mathrm{g}$ & $242 \pm 14$ & $238 \pm 10$ \\
\hline Sesame oil & 3 & 우 & $.5 \mathrm{~cm}^{3}$ & $221 \pm 26$ & $219 \pm 25$ \\
\hline
\end{tabular}

${ }^{1}$ Standard deviation. Prop. $=$ propionate. Dip. $=$ dipropionate. $\mathrm{DCA}=$ desoxy. corticosterone acetate.

nearly aseptic conditions as possible. One-third of the rats in each of the above groups received 1,000 units of penicillin daily by subcutaneous injection for three days after implantation in order to combat any infection which might occur.

For study of the effect of circulating hormones on the foreign body reaction, a sterilized pellet of cholesterol was implanted aseptically behind one eye of each rat. Subsequently, for 10-12 days, the rats received daily subcutaneous

\footnotetext{
${ }^{2}$ We extend our appreciation to the following donors for the hormones used: free cortisone and cortisone acetate (Cortone), Merck and Co., Ine., 11-desoxycorticosterone and desoxycorticosterone acetate (Percorten), alpha-estradiol dipropionate (Di-Ovocylin), testosterone propionate (Perandren), Ciba Pharmacentical Produets, Inc.; and testosterone and alpha-estradiol, The Schering Corporation.
} 
injections of hormones or comparable volumes of the fluids used as solvents according to the plan shown in table 1. A large variation is evident in the body weights of certain groups because the figure is based on the weights for two experiments in which different sexes were used. In each experiment all body weights fell within a range of $15 \mathrm{gm}$ but between the two experiments there was a wide difference.

All implantation sites were excised 10 or 12 days after the pellets had been implanted and were fixed in Bouin's or Orth's fluid. The tissue was sectioned serially and stained with Harris' hematoxylin and the Masson procedure ('28) or with the periodic acid-leucofuchsin (PAS) technique of Hotchkiss ('48). Body weights were observed at the beginning and termination of all experiments. Since the amount of hormone contained in the implanted pellets was too small to affect the body weight, these values are presented only for the experiments in which the hormones were administered by subcutaneous injection.

\section{OBSERVATIONS}

\section{The implantation of pellets of hormones}

The magnitude of the connective tissue reaction around an individual pellet varied greatly in different locations, the pressure exerted by surrounding structures appearing to be an important modifying factor. Nevertheless, it was clear that some of the steroid hormones altered this response significantly when compared with the response induced by cholesterol.

Around cholesterol pellets a cellular rim had formed at 12 days which was composed chiefly of epithelioid macrophages, many of which had fused to form multinucleated giant cells (fig. 1). The latter were most numerous in the portion of the capsule adjacent to the pellet. The cytoplasm of both macrophages and giant cells stained with PAS. The cytocentrum of the giant cells possessed a stippled appearance. Among these cells were newly-formed fibroblasts and variable numbers of neutrophiles. New capillaries had formed at the periphery of the rim. The reaction to pellets of testosterone was qualita- 
tively similar to that elicited by cholesterol (fig. 4) except that it often seemed to be more intense with a thicker cellular border being formed.

Pellets of cortisone suppressed all aspects of the connective tissue response as compared with that induced by cholesterol and testosterone. The cellular rim was thinner (fig. 2). Most of the epithelioid macrophages were smaller, and their cytoplasm stained less intensely with aniline blue or PAS. Their nuclei were more compact and of irregular shape, in many cases being pycnotic. Clusters of cells, which appeared to be modified macrophages, occurred at the external border of the capsule. In Bouin-fixed preparations they were highly vacuolated and contained pycnotic or fragmented nuclei. PAS staining after fixation in Orth's fluid showed that some of these vacuoles contained a substance which recolorized the Schiff reagent. Other brown-colored inclusions were probably pigment.

As compared with the response elicited by cholesterol or testosterone, giant cells were less numerous. Frequently, these giant cells were enlarged and in some cases appeared to be fusing with each other. The cytoplasm in the region of the cytocentrum was dense but stained less intensely. The nuclei were usually more numerous, smaller and more compact. Neutrophiles were never observed in the neighborhood of a pellet of cortisone and neo-formation of fibroblasts and capillaries was inhibited almost completely.

Pellets of desoxycorticosterone resembled cortisone in suppressing the connective tissue response although some outstanding differences were apparent (fig. 3). The peripheral macrophages were numerous and large. Their cytoplasm was scant but did not become as clear as in the cells near pellets of cortisone. A rim of amorphous material which stained with aniline blue and PAS appeared at the inner border of the cellular rim. This substance seemed to have arisen from degeneration of the neighboring cells since many of them possessed pycnotic nuclei. Rarely were giant cells observed, desoxycorti- 
costerone appearing to suppress their formation almost completely.

As compared with cholesterol, pellets of estrogen induced only a mild suppression of the connective tissue response (fig. 5). All cellular constituents of the rim were present. Estrogen may have stimulated the fusion of epithelioid macrophages to form giant cells since there appeared to be a higher proportion of the latter.

\section{The subcutaneous administration of hormones}

Of all hormones studied by subcutaneous injection, only cortisone modified significantly the foreign body reaction elicited by implanted pellets of cholesterol. The histology of this suppression was similar in some respects to that which occurred around pellets of cortisone as described previously. Although giant cells were not swollen, both they and the macrophages were reduced in number with the latter cells being affected more significantly. This inhibition was even more striking in areas where the cholesterol pellet had been fragmented during implantation. Extensive cellular infiltration, proliferation of fibroblasts and formation of new capillaries occurred in these areas in the control rats which were treated with $0.9 \%$ $\mathrm{NaCl}$ or aqueous behicle (fig. 6). These changes were minimal after treatment with cortisone (fig. 7), although some giant cells were always present.

Subcutaneously injected desoxycorticosterone and testosterone did not alter the reaction of connective tissue to implanted pellets of cholesterol. Treatment with alpha-estradiol dipropionate induced a quantitative reduction of the reaction in only a few cases. Giant cells, neutrophiles, and newly formed fibroblasts and capillaries were always present.

\section{DISCUSSION}

It may be assumed that the modification of the foreign body reaction around implanted pellets of cortisone is a direct local effect. In order to induce significant structural changes by systemic administration of cortisone, much larger doses are 
required. Many aspects of this suppression, as well as of that which occurred after systemic administration of the hormone, are in agreement with the known influence of cortisone on traumatized connective tissue (Ingle and Baker, '53). These responses include interference with the mobilization of neutrophiles and macrophages to an injured area, and retarded formation of new fibroblasts and capillaries. In this study, cortisone suppressed the foreign body reaction when implanted as a pellet, as well as when injected subcutaneously. This observation agrees with that of Meier, Gross, Desaulles and Schär ('52) who injected cortisone acetate and studied its local action by placing the crystals in a pellet of cotton which was implanted beneath the skin. Similarly, systemic administration of cortisone inhibits the development of a granuloma around particles of quartz implanted under the skin (Polemann, '51) or in the peritoneal cavity (Curran, ' 52 ; Margarey and Gough, '52). Although formation of giant cells is not induced by this means, Margarey and Gough ('52) observed retarded fibrosis which was marked in the mouse, less evident in the rat and rabbit, and absent in the guinea pig. Reduced cellular infiltration occurred in the experiments of Polemann ('51).

The suppression in formation of new capillaries around pellets of cortisone did not interfere seriously with absorption of the hormone. In preliminary experiments in which pellets were left in situ for periods longer than 12 days, the cortisone was absorbed completely. This conclusion is compatible with the observation of Henderson et al. ('51) that a rapid clinical response is elicited by pellets of cortisone implanted into patients suffering from rheumatoid arthritis. However, there was no prolongation of action as compared with that which follows implantation of pellets of other steroid hormones.

In contrast to cortisone, desoxycorticosterone suppressed the foreign body reaction locally when it was used as an implanted pellet but failed to do so after systemic administration. Meier et al. ('53) observed the same effect when desoxycorticosterone was placed in a pellet of cotton. Other observations reveal also that the direct effect of desoxycorticosterone on 
fibro-elastic connective tissue is a suppressing or injurious one. In tissue cultures, it damages fibroblasts to a greater extent than does cortisone (Cornman, '51; Meier et al., '52). When applied directly to rat skin, desoxycorticosterone inhibits growth of hair, modifies the structure of dermal connective tissue (Baker, '51; Whitaker and Baker, '51), and accelerates the spreading action of hyaluronidase (Hayes and Bridgman, '51), in all of these respects being similar in action but less effective than cortisone. But according to Taubenhaus ('52), when desoxycorticosterone is mixed with turpentine, it exerts no local effect on the formation of granulation tissue around the injection site.

Our observation that subcutaneously injected desoxycorticosterone did not intensify the foreign body reaction around implanted pellets of cholesterol is contrary to the observations of others. Meier et al. ('52) reported that it accentuates the foreign body reaction. According to Taubenhaus and Amromin ('49), prolonged prior treatment with desoxycorticosterone accelerates the formation of granulation tissue around turpentine abscesses. Similarly, Selye ('50) holds that this hormone conditions or stimulates the responsivity of fibro-elastic connective tissue in the development of inflammatory reactions. Since desoxycorticosterone has the contrary effect when used locally, one would have to assume that after systemic administration, the hormone acts first at some intermediary focus (anterior hypophysis?) or that the effect on connective tissue is elicited by a metabolite of desoxycorticosterone.

\section{SUMMARY}

A study was made of the connective tissue reaction around implanted pellets of cholesterol, cortisone, desoxycorticosterone, alpha-estradiol and testosterone and also around pellets of cholesterol as modified by subcutaneous administration of the hormones listed. The appearance of epithelioid macrophages, giant cells and formation of new fibroblasts and macrophages were suppressed in the neighborhood of implanted pellets of cortisone. Subcutaneous injection of this hormone in- 
duced a similar suppression around implanted pellets of cholesterol. The reaction was inhibited around implanted pellets of desoxycorticosterone but the hormone had little effect when injected. Alpha-estradiol and testosterone produced less significant changes after either method of administration, the former tending to inhibit and the latter, to stimulate the reaction.

\section{I.ITERATURE CITED}

BAKER, B. L. 1951 The relationship of the adrenal, thyroid, and pituitary glands to the growth of hair. Ann. N. Y. Acad. Sci., 53: 690-707.

CoRNMAN, I. 1951 Selective damage to fibroblasts by desoxycorticosterone in cultures of mixed tissues. Science, $113: 37-39$.

CURRAN, R. C. 1952 The effect of cortisone on the reaction of the mouse peritoneum to quartz. Brit. J. Exp. Path., 33: 82-86.

Hayes, M. A., and R. M. BRIDgman 1951 Dermal spreading of hyaluronidase as influenced by prolonged local treatment with certain steroid hormones. Proe. Soe. Exp. Biol. and Med., 77 : 597-599.

Henderson, E., J. W. Gray, M. Weinberg and T. Z. Merrick 1951 Subcutaneous implantation of cortisone pellets in rheumatoid arthritis. Seience, 114: 243 .

Hotchkiss, R. D. 1948 A microchemical reaction resulting in the staining of polysaccharide structures in fixed tissue preparations. Arch. Biochem., $16: 131-141$.

INGLE, D. J., AND B. L. BAKFr 1953 Physiological and therapeutic effects of corticotropin (ACTH) and cortisone. Charles C Thomas, Springfield.

MARgarey, F. R., AND J. GOUgF 1952 The effect of cortisone on the reaction to qual tz in the peritoneal cavity. Brit. J. Exp. Path., 33: 76-81.

Masson, P. 1928 Carcinoids (argentaffin-cell tumors) and nerve hyperplasia of the appendicular mueosa. Am. J. Path., 4: 181-212.

MeIer, R., F. Gross, P. DeSAULles aNd B. Schär 1952 Vergleich der celluliiren Wirkung versehiedener Steroide in vitro und in vivo. Bull. schweiz. Akad. med. Wiss., 8: 34-53.

PolemanN, G. 1951 Zur Wirkung des Cortison auf das experimentelle Quarzgranulom der Maus. A rch. Derm. u. Syph., 193: 257-266.

Selye, H. 1950 Stress, Acta, Inc., Montreal, Canada.

mAUBENHAUS, M. 1952 Hormonal synergism and antagonism in tissue reactions. Bull. schweiz. Akad. med. Wiss., 8: 54-59.

TaUbenhaus, M., AND G. D. AMromin 1949 Influence of steroid hormones on granulation tissue. Endocrinology, 44: 359-367.

WhITAKER, W. L., AND B. L. BAKER 1951 The relative effectivenss of adrenal cortical holmones in the inhibition of laair growth in the rat. Univ. of Mich. Med. Bull., 17: 384-390. 
PLATE 
PLATE 1

\section{FXPLANATION OF FIGURES}

All specimens illustrated were fixed in Bouin's fluid and stained with Harris' hematoxylin and Masson. Figures 1-5 are of the cellular rim around implanted pellets of cholesterol and steroid hormones $(\times 760)$. In all eases, the pellet was located at the upper surface. Figures 6 and 7 illustrate the reaction in the neighborhood of fragmented cholesterol pellets when cortisone acetate or its suspending rehicle were injected subcutaneously $(\times 305)$.

1 Cholesterol. Many small epithelioid macrophages, neutrophiles and fibroblasts are present. A giant cell is at the upper margin and newly formed capillaries are at the bottom.

2 Cortisone. In the center is a huge giant cell with many nuclei and a less dense cytoplasn as compared with those in figure 1 . The macrophages at the upper margin are few, small and in many cases, have pyenotic nuclei; those below the giant cell are highly racuolated.

3 Desoxycorticosterone. The macrophages are large and contain little cytoplasm. At the upper margin is an amorphous material stained with aniline blue. The line represents the boundary between the rim of cellular reaction and surrounding connective tiss.e

4 Testosterone. 'The reaction is similar to that induced by cholesterol, many giant cells being present at the upper border.

5 Alpha-estradiol. A giant cell is at the upper right hand comer.

6 Aqueous vehicle no. 1. Some giant cells are forming at the left. Many macrophages and fibroblasts have appeared.

7 Cortisone acetate. The cellular reaction is suppressed except for the formation of some giant cells. The large spaces were oceupied by fragments of cholesterol. 

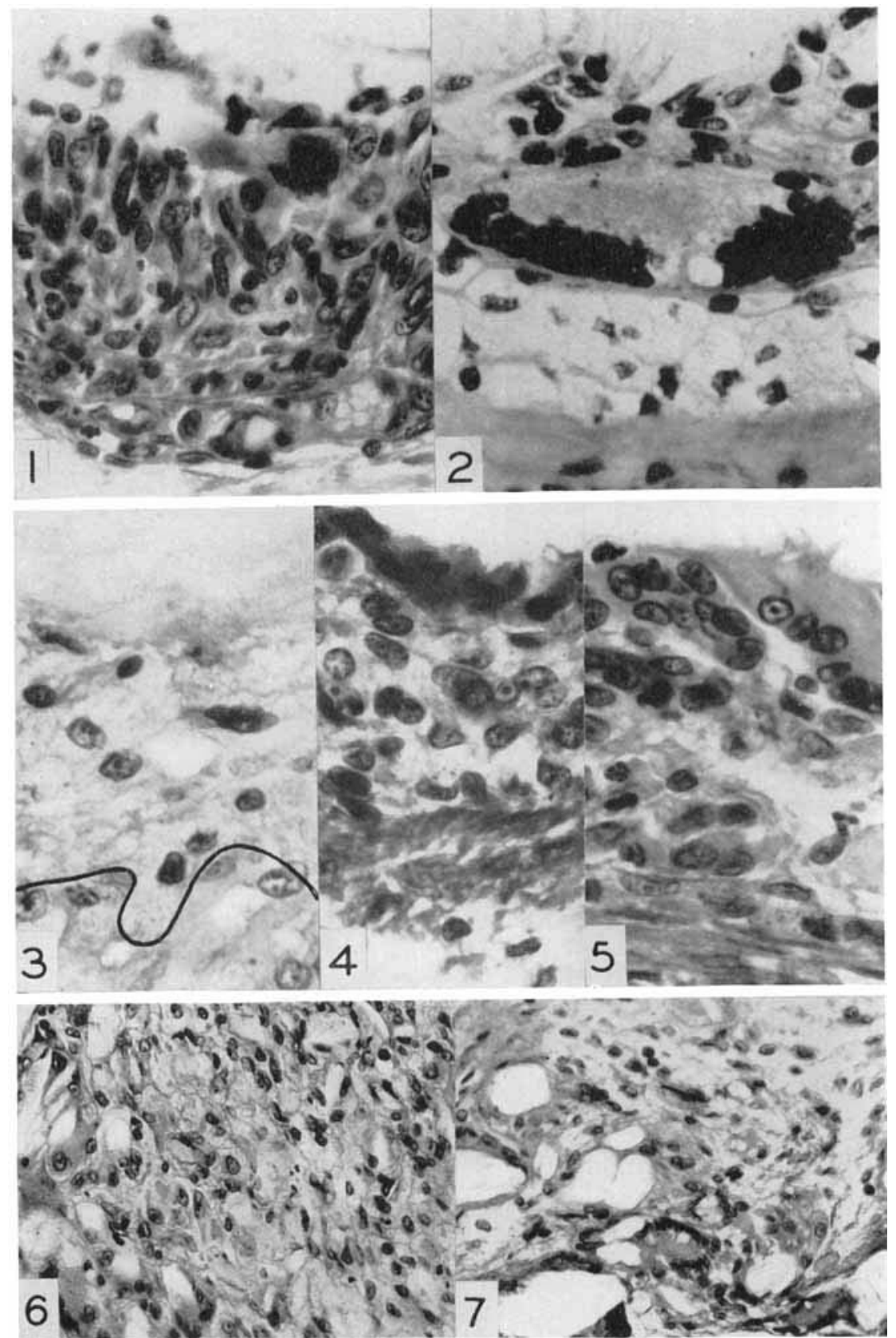